\title{
ANALISA KOORDINASI SINYAL ANTAR SIMPANG DENGAN MENGGUNAKAN SOFTWARE TRANSYT 14 (Studi Kasus Simpang Empat dan Simpang BPD Kota Lhokseumawe)
}

\author{
Aisyah Putri Elmanda ${ }^{1)}$, Zulfhazli ${ }^{2)}$, Said Jalalul Akbar ${ }^{3)}$ \\ ${ }^{1)}$ Alumni Jurusan Teknik Sipil, ${ }^{2), 3)}$ Jurusan Teknik Sipil, Universitas Malikussaleh \\ email: ${ }^{1)}$ icaelmanda@gmail.com, ${ }^{2}{ }^{2}$ zulfhazli.abdullah@gmail.com, \\ 3)jaakdanil@gmail.com
}

\begin{abstract}
Abstrak
Koordinasi antar simpang secara umum dimaksudkan untuk meningkatkan pelayanan suatu jaringan jalan, mengurangi waktu tunda dan waktu berhenti kendaraan. Setelah melakukan antrian waktu merah pada salah satu persimpangan, kendaraan diharapkan akan memperoleh waktu hijau pada persimpangan berikutnya. Sistem koordinasi demikian belum diterapkan di Jalan Merdeka Kota Lhokseumawe. Sebagai jalan utama pada pada lintasan tersebut ada dua persimpangan bersinyal yaitu, Simpang Empat dan Simpang BPD. Akibat belum adanya koordinasi antar persimpangan tersebut, sering kendaraan yang baru lolos dari Simpang Empat harus berhenti dan menunggu fase hijau lagi pada Simpang BPD dan begitu juga arah sebaliknya. Sehingga antrian, waktu tundaan dan waktu berhenti yang panjang terutama pada jam puncak tidak dapat dihindari. Metode yang digunakan pada penelitian ini yaitu Metode Manual Kapasitas Jalan Indonesia (MKJI 1997), sementara untuk koordinasi lampu antar simpang menggunakan bantuan perangkat lunak Transyt 14 berpedoman pada metode Transport and Road Research Laboratory (TRRL) Inggris. Transyt 14 digunakan untuk mengevaluasi kinerja persimpangan pada kondisi eksisting serta membuat beberapa alternatif koordinasi dengan performance index (PI) sebagai kriteria utama.Hasil penelitian untuk alternatif terbaik dibandingkan kondisi eksisting diperoleh waktu siklus 100 detik,degree of saturation turun $17,07 \%$, antrian berkurang $14,15 \%$, waktu tunda berkurang $57,38 \%$, jumlah henti turun 20,57\%, dan tingkat pelayanan dapat ditingkatkan dari C menjadi B.
\end{abstract}

Kata kunci : Koordinasi, Simpang Bersinyal, Transyt 14, level of servise

\section{Pendahuluan}

Tidak adanya koordinasi lampu lalu-lintas antar simpang akan mengakibatkan kendaraan mempunyai kemungkinan lebih besar untuk bertemu lampu merah saat memasuki dua simpang berurutan, pada kondisinya antrian kendaraan sudah menunggu pada masing-masing simpang teresebut. Pada volume jam puncak sering lampu hijau tidak terlewati seluruh antrian kendaraan pada tiap-tiap lengan simpang yang mengakibatkan kendaraan harus menunggu sampai siklus berikutnya, pada kondisi tertentu kendaraan harus menunggu beberapa siklus untuk melewati suatu simpang.

Koordinasi antar simpang bersinyal belum dijumpai pada pengaturan simpang bersinyal yang ada di Jl. Merdeka Kota Lhokseumawe Provinsi Aceh. Pada ruas jalan tersebut terdapat lebih dari dua persimpangan bersinyal, yaitu Simpang Empat dan Simpang BPD, jarak antara Simpang tersebut sekitar $400 \mathrm{~m}$. Kondisi pada saat ini kedua persimpangan tersebut belum dikoordinasikan, akibat yang ditimbulkan adalah terjadinya kendaraan yang baru lolos dari Simpang BPD

Analisa Koordinasi Sinyal Antar Simpang Dengan Menggunakan Software Transyt 14 - Aisyah Putri Elmanda ${ }^{1)}$, Zulfhazli ${ }^{2)}$, Said Jalalul Akbar ${ }^{3)}$ 
harus berhenti menunggu fase hijau lagi pada Simpang Empat dan sebaliknya, sehingga antrian, waktu tundaan dan waktu berhenti yang panjang terutama pada jam puncak tidak dapat dihindari.

\section{Tinjauan Kepustakaan}

\subsection{Landasan Teori MKJI}

Manual Kapasitas Jalan Indonesia (MKJI) memuat fasilitas jalan perkotaan, semi perkotaan, luar kota dan jalan bebas hambatan. Tipe fasilitas yang tercakup dan ukuran penampilan lalu-lintas selanjutnya disebut perilaku lalu-lintas atau kualitas lalu-lintas. Tujuan analisa MKJI adalah untuk dapat melaksanakan Perancangan (planning), Perencanaan (design), dan Pengoperasionalan lalu-lintas (traffic operation) Simpang bersinyal, Simpang tak bersinyal, bagian jalinan, bundaran dan ruas jalan (jalan perkotaan, jalan luar kota dan jalan bebas hambatan).

\subsection{Data masukan}

\subsubsection{Kondisi geometrik}

Berisi tentang informasi lebar jalan, lebar bahu jalan, lebar median dan arah untuk tiap lengan Simpang. Kondisi lingkungan ada tiga tipe, yaitu komersial, pemukiman dan akses terbatas. Menurut MKJI 1997, kondisi geometrik pengaturan lalu lintas dan kondisi lingkungan perhitungannya dikerjakan secara terpisah untuk setiap pendekat. Satu lengan Simpang dapat terdiri lebih dari satu pendekat, yaitu dipisahkan menjadi dua atau lebih sub pendekat. Hal ini terjadi jika gerakan belok kanan dan belok kiri mendapat sinyal hijau pada fase yang berlainan dengan lalu-lintas yang lurus atau jika dipisahkan secara fisik dengan pulau-pulau lalu-lintas dalam pendekat.

\subsubsection{Kondisi arus lalu lintas}

Arus lalu-lintas merupakan jumlah kendaraan yang melintasi suatu titik pada suatu ruas jalan dalam waktu tertentu dengan membedakan arah dan lajur.Satuan arus adalah kendaraan/waktu atau smp/waktu. Perhitungan dilakukan per satuan jam untuk satu atau lebih periode, misalnya didasarkan pada kondisi arus lalu-lintas rencana jam puncak pagi, siang dan sore. Arus lalu-lintas (Q) untuk setiap gerakan (belok kiri $\mathrm{Q}_{\mathrm{LT}}$, lurus $\mathrm{Q}_{\mathrm{ST}}$ dan belok kanan $\mathrm{Q}_{\mathrm{RT}}$ ) dikonversi dari kendaraan per jam menjadi satuan mobil penumpang (smp) per jam dengan menggunakan ekivalen kendaraan penumpang (emp) untuk masing-masing pendekat terlindung dan terlawan. Untuk nilai ekivalen mobil penumpang dapat dilihat pada tabel berikut:

Tabel 1 Nilai Ekivalen Mobil Penumpang (emp)

\begin{tabular}{|l|c|c|}
\hline \multirow{2}{*}{\multicolumn{1}{|c|}{ Jenis Kendaraan }} & \multicolumn{2}{c|}{ emp untuk tipe pendekat } \\
\cline { 2 - 3 } & Terlindung & Terlawan \\
\hline Kendaraan Ringan (LV) & 1,0 & 1,0 \\
\hline Kendaraan Berat (HV) & 1,3 & 1,3 \\
\hline Sepeda Motor (MC) & 0,2 & 0,4 \\
\hline
\end{tabular}

Sumber: MKJI 1997

\subsection{Kapasitas}

Kapasitas dapat didefinisikan sebagai arus lalu lintas yang dapat dipertahankan pada suatu bagian jalan dalam kondisi tertentu, dalam kendaraan/ 
jam atau smp/jam. Faktor-faktor yang mempengaruhi kapasitas suatu Simpang adalah kondisi fisik Simpang dan operasi, yaitu ukuran dan dimensi lebar jalan, kondisi parkir dan jumlah lajur, kondisi lingkungan, yaitu faktor jam sibuk pada suatu Simpang, karakteristik gerakan lalu lintas, yaitu gerakan membelok dari kendaraan, karakteristik lalu lintas kendaraan berat, yaitu truk dan bus melewati Simpang.Menurut Manual Kapasitas Jalan Indonesia (MKJI) 1997.

$$
C=S x \frac{g}{c}
$$

\subsection{Derajat kejenuhan}

Derajat kejenuhan adalah rasio arus terhadap kapasitas jalan. Biasanya digunakan sebagai faktor kunci dalam penentuan perilaku lalu-lintas pada suatu segmen jalan dan Simpang. Dari nilai derajat kejenuhan ini dapat diketahui segmen jalan tersebut akan memiliki kapasitas yang cukup atau tidak. Menurut Manual Kapasitas Jalan Indonesia (MKJI) 1997. Persamaan untuk mencari besarnya kejenuhan adalah sebagai berikut:

$$
D_{S}=\frac{Q s m p}{C}
$$

\subsection{Perilaku Lalu-Lintas}

\subsubsection{Panjang Antrian}

Antrian suatu kendaraan adalah gangguan yang terjadi secara berkala akibat adanya sinyal atau lampu lalu-lintas pada persimpangan. Atau dengan kata lain, antrian merupakan banyaknya kendaraan yang menunggu pada suatu persimpangan. Panjang antrian menggunakan hasil perhitungan derajat kejenuhan untuk menghitung jumlah antrian smp (NQ1) yang tersisa dari fase hijau sebelumnya.

Untuk DS>0,5:

$$
N Q 1=0,25 x C x\left((D s-1)+\sqrt{\left.(D s-1)^{2}+\frac{8 x(D s-0,5}{C}\right)}\right) .
$$

Untuk DS $\leq 0,5:$ NQ1 $=0$

Menghitung jumlah antrian smp yang datang selama fase merah (NQ2)

$$
N Q 2=C \times \frac{1-G R}{1-G R \times D s} \times \frac{Q}{3600}
$$

Menghitung panjang antrian (QL) degan mengalikan $\mathrm{NQ}_{\max }$ dengan luas rata-rata yang dipergunakan per $\operatorname{smp}\left(20 \mathrm{M}^{2}\right)$ kemudian bagilah dengan lebar masuknya.

$$
Q_{L}=\frac{N Q \max \times 20}{W m a s u k}
$$

\subsubsection{Kendaraan Terhenti (NS)}

Waktu henti didefinisikan sebagai waktu yang dibutuhkan oleh angkutan umum untuk berhenti pada suatu titik pengamatan tertentu. Perhitungan angka henti (NS) masing-masing pendekat yang didefinisikan sebagai jumlah rata-rata berhenti per smp (termasuk berhenti berulang dalam antrian), dengan rumus: 


$$
N_{S V}=\frac{0,9 N Q}{Q \times C} \times 3600
$$

Perhitungan jumlah kendaraan terhenti (Nsv) masing-masing pendekat dengan rumus;

$$
N s v=Q \times N S(\text { smp/jam })
$$

Dan perhitungan angka henti seluruh simpang dengan cara membagi jumlah kendaraan terhenti pada seluru pendekat dengan arus simpang total Q dalam kend/jam dengan rumus:

$$
N S_{T O T}=\frac{\Sigma N w}{Q T E}
$$

\subsection{Tundaan (delay)}

Tundaan (delay) adalah waktu tempuh tambahan yang diperlukan untuk melalui Simpang dibandingkan lintasan tanpa melalui suatu Simpang. Tundaan lalu-lintas (DT), akibat interaksi lalu-lintas dengan gerakan yang lain dalam simpang, yaitu dapat dihitung dengan rumus:

$$
D T=c x A+\frac{N Q 1 \times 3500}{c}
$$

Tundaan geometri (DG) akibat perlambatan dan percepatan kendaraan yang yang membelok di Simpang atau yang berhenti oleh lampu merah, yaitu dapat dihitung dengan rumus;

$$
D G_{j}=\left(I-p_{s v}\right) \times p_{T} \times 6+\left(P_{s v} \times 4\right) \text {. }
$$

Tundaan rata-rata seluruh Simpang $\left(\mathrm{D}_{\mathrm{I}}\right)$, yaitu dengan rumus;

$$
D I=\frac{\Sigma(Q x D)}{Q T o t}
$$

\subsection{Level of service (LOS)}

Pada umumnya tujuan dari adanya tingkat pelayanan adalah untuk melayani seluruh kebutuhan lalu-lintas (demand) dengan sebaik mungkin. Baiknya pelayanan dapat dinyatakan dalam tingkat pelayanan (Level Of Service). Level Of Service (LOS) merupakan ukuran kualitas sebagai rangkaian dari beberapa faktor yang mencakup kecepatan kendaraan dan waktu perjalanan, kebebasan untuk manuver, keamanan, kenyamanan mengemudi dan ongkos operasi (operation cost), sehingga LOS sebagai tolak ukur kualitas suatu kondisi lalu-lintas, maka volume pelayanan harus kurang dari kapasitas jalan itu sendiri.

Tabel 2 Tundaan Simpang Rata-Rata (LOS)

\begin{tabular}{|c|c|c|}
\hline Tingkat Pelayanan & Rasio $(\mathbf{V} / \mathrm{C})$ & Karakteristik \\
\hline $\mathrm{A}$ & $<0,60$ & Baik sekali \\
\hline $\mathrm{B}$ & $0,60<\mathrm{V} / \mathrm{C}<0,70$ & Baik \\
\hline $\mathrm{C}$ & $0,70<\mathrm{V} / \mathrm{C}<0,80$ & Sedang \\
\hline $\mathrm{D}$ & $0,80<\mathrm{V} / \mathrm{C}<0,90$ & Kurang \\
\hline $\mathrm{E}$ & $0,90<\mathrm{V} / \mathrm{C}<1$ & Buruk \\
\hline $\mathrm{F}$ & $>1$ & Buruk sekali \\
\hline
\end{tabular}

Tingkat tundaan dapat digunakan sebagai indikator tingkat pelayanan, baik untuk setiap pendekat maupun seluruh persimpangan. Kaitan antara tingkat pelayanan dan lamanya tundaan diperlihatkan pada Tabel 2 


\section{$2.8 \quad$ TRANSYT 14}

Transyt 14(Traffic Network Study Tool) adalah program computer sebagai alat bantu untuk mengkoordinasi simpang bersinyal waktu tetap (pre-time signal control). Transit 14 menggunakan metode green bandwitdth sebgai konsep dasar untuk koordinasi simpang bersinyal.Program ini dikeluarkan oleh Tranport and Road Research Laboratory Inggris.

Program Transyt 14 mempunyai dua elemen utama yaitu :

\section{Model Lalu-lintas}

Model lalu-lintas menggambarkan pola pergerakan atau tingkah laku lalulintas pada jaringan jalan yang mempunyai satu persimpangan bersinyal atau lebih. Model ini memprediksikan performance index (PI) untuk perencanaan waktu tetap. PI merupakan ukuran total harga kemacetan lalu-lintas yang merupakan kombinasi waktu total tundaan(delay) dan jumlah berhenti (stop) kendaraan.

\section{Optimasi Sinyal Lampu Lalu-lintas}

Optimasi merupakan proses penyesuaian waktu sinyal, evaluasi dan penggunaan model. Penyesuaian itu dapat mengurangi atau meningkatkan nilai PI.Hasil penyesuaian yang digunakan adalah yang menghasilkan nilai PI terkecil walaupun fase hijau yang diperoleh adalah minimum.

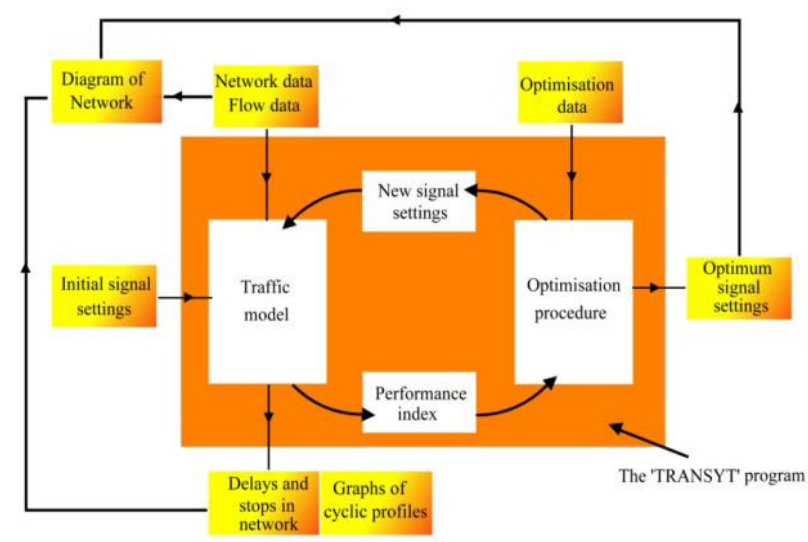

Gambar 1 Struktur program Transyt 14

Sumber: Binning et.al, 2011

Optimasipada Transyt 14 bertujuan untuk meminimumkan performance index dengan cara menurunkan tundaan dan jumlah stop yang terjadi. Optimasi yang dilakukan Transyt 14 adalah signal offset dan waktu hijau di setiap persimpangan.

\section{Performance Index}

Performance index merupakan kombinasi dari jumlah total tundaan dan total stop pada semua link yang ditinjau dan juga dijadikan sebagai ukuran biaya kemacetan. Performance index (PI) dihitung dengan persamaan berikut:

$P I=\sum_{i=1}^{N} \quad$ W. wi $\cdot d i+\frac{k}{100} k i \cdot s i$

Keterangan:

$\mathrm{N}=$ jumlah link;

$\mathrm{W}=$ biaya per tundaan $(\mathrm{smp} / \mathrm{jam})$

Analisa Koordinasi Sinyal Antar Simpang Dengan Menggunakan Software Transyt 14 - Aisyah Putri Elmanda ${ }^{1)}$, Zulfhazli ${ }^{2)}$, Said Jalalul Akbar ${ }^{3)}$ 
$\mathrm{K}=$ biaya tiap $100 \mathrm{smp}$ stop

$\mathrm{Wi}=$ bobot tundaan pada link $\mathrm{i}(\%)$

di $=$ tundaan pada link i (detik)

$\mathrm{ki}=$ bobot stop pada link $\mathrm{i}(\%)$;

si $=$ jumlah stop pada link i, satuan 100 jumlah stop.

\section{Degree of Saturation}

Degree of Saturation(DS)atau derajat kejenuhan pada simpang bersinyal merupakan gambaran volume lalu-lintas yang lewat dibandingkan dengan kapasitas simpang.Degree of saturation dirumuskan sebagai berikut:

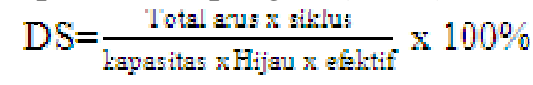

Jika DS lebih dari $100 \%$ ini berarti volume lalu-lintas pada persimpangan telah melewati kapasitas yang mampu dilewatkan.Akibatnya sebagian kendaraan harus menunggu fase hijau berikutnya untuk memperoleh kesempatan lewat.

\section{Signal Offset}

Koordinasi pada Transyt 14 dilakukan dengan cara menghubungkan semua stage change time ke waktu nol. Stage change time pada persimpangan adalah waktu dimana perioda hijau pada satu fase pertama dimulai.

\section{Optimasi lampu hijau}

Selama optimasi offset dijalankan semua waktu perubahan fase di node bergeser beraturan. Hasilnya waktu hijau yang telah ditetapkan untuk setiap fase akan berubah. Transyt 14 mengoptimasi waktu hijau berbagai fase untuk mengurangi performance index.

\section{Level of Service (LoS)}

Transyt 14 menentukan level of service (LoS) atau tingkat pelayanan persimpangan bersinyal berpedoman pada Highway Capacity Manual (2000). LoS ini ditetapkan berdasarkan waktu delay.

\section{Metode Penelitian}

\subsection{Pengumpulan Data}

\subsubsection{Data Primer}

Data primer yaitu data yang diperoleh langsung dari pengamatan di lokasi peneletian pada kedua simpang, yang meliputi:

a) Volume kendaraan yang melewati setiap lengan simpang, dimana dalam hal ini dilakukan pencatatan kendaraan berdasarkan jenis dan arah pergerakan.

b) Jumlah fase dan waktu sinyal pada masing-asing simpang.

c) Kondisi geometrik, pembagian jalur, dan jarak antar simpang.

d) Lingkungan simpang yang diamati secara visual.

\subsubsection{Data Sekunder}

Data sekunder adalah data yang diperoleh dari beberapa instansi terkait dan dari beberapa penelitian tentang ruas jalan yang diteliti sebelumnya.Data sekunder tersebut berupa jumlah penduduk Kota Lhokseumawe. 


\subsection{Penentuan Waktu Penelitian}

Waktu pengamatan dilakukan pada saat jam sibuk (di mana terdapat volume lalu-lintas yang padat/maksimum). Dari hasil fluktuasi penelitian-penelitian sebelumnya maka diambil waktu pengamatan sesuai dengan kebutuhan

\section{Hasil dan Pembahasan}

\subsection{Data Masukan}

Kondisi geometrik Simpang Empat yaitu pada persimpangan tersebut terdapat median jalan pada pendekat B dan D. Untuk kondisi lingkungan terdapat pertokoan dan beberapa warung disepanjang tepi ruas jalan tersebut, sehingga empat lengan tersebut termasuk dalam kategori tipe lingkungan jalan Komersial (KOM). Kondisi geometrik Simpang BPD diperlihatkan Tabel 3 dan Tabel 4.

Tabel 3 Kondisi geometrik Simpang Empat

\begin{tabular}{|c|c|c|c|c|c|}
\hline $\begin{array}{c}\text { Kode } \\
\text { pendekat }\end{array}$ & $\begin{array}{c}\text { Tipe } \\
\text { lingkungan } \\
\text { jalan }\end{array}$ & $\begin{array}{c}\text { Median } \\
\text { Ya/Tidak }\end{array}$ & $\mathrm{W}_{\text {LTOR }}$ & $\begin{array}{c}\text { Masuk } \\
\mathrm{W}_{\text {MASUK }}\end{array}$ & $\begin{array}{c}\text { Keluar } \\
\mathrm{W}_{\text {KELUAR }}\end{array}$ \\
\hline $\mathrm{A}$ & COM & $\mathrm{T}$ & - & 6,20 & 3,00 \\
\hline $\mathrm{B}$ & COM & $\mathrm{Y}$ & - & 7,50 & 9,70 \\
\hline $\mathrm{C}$ & $\mathrm{COM}$ & $\mathrm{T}$ & 5,0 & 3,00 & 6,20 \\
\hline $\mathrm{D}$ & COM & $\mathrm{Y}$ & 6,4 & 11,55 & 12,10 \\
\hline
\end{tabular}

Tabel 4 Kondisi geometrik Simpang BPD

\begin{tabular}{|c|c|c|c|c|c|}
\hline $\begin{array}{c}\text { Kode } \\
\text { pendekat }\end{array}$ & $\begin{array}{c}\text { Tipe lingkungan } \\
\text { jalan }\end{array}$ & $\begin{array}{c}\text { Median } \\
\text { Ya/Tidak }\end{array}$ & $\mathrm{W}_{\text {LTOR }}$ & $\begin{array}{c}\text { Masuk } \\
\mathrm{W}_{\text {MASUK }}\end{array}$ & $\begin{array}{c}\text { Keluar } \\
\mathrm{W}_{\text {KELUAR }}\end{array}$ \\
\hline $\mathrm{A}$ & COM & $\mathrm{T}$ & - & 6,0 & 6,0 \\
\hline $\mathrm{B}$ & COM & $\mathrm{Y}$ & - & 6,0 & 9,0 \\
\hline C & COM & $\mathrm{T}$ & - & 6,0 & 6,0 \\
\hline $\mathrm{D}$ & COM & $\mathrm{Y}$ & - & 6,0 & 9,0 \\
\hline
\end{tabular}

\subsection{Volume dan distribusilalulintas}

Lalulintas yangmelewati persimpangan bersinyal di Jalan Merdeka bervariasi, yaitu sepeda motor, mobil pribadi, mikrobus, bus, truk dan becak mesin.Volume lalulintas simpang dalam satuan mobil penumpang (smp) diperlihatkan pada Tabel 5 dan Tabel 6

Tabel 5 Arus lalu-lintaspada Simpang Empatjam puncak

\begin{tabular}{|c|c|c|c|c|c|c|c|}
\hline \multirow{2}{*}{ Pendekat } & \multirow{2}{*}{ Waktu } & \multirow{2}{*}{ Pergerakan } & \multicolumn{3}{|c|}{ Jenis Kendaran } & \multicolumn{2}{|c|}{ Volume } \\
\hline & & & $\mathrm{LV}$ & $\mathrm{HV}$ & $\mathrm{MC}$ & Kend & Smp \\
\hline \multirow{4}{*}{$\mathrm{U}$} & \multirow{4}{*}{$07.00-08.00$} & $\begin{array}{ll}\text { Lurus } & (\mathrm{ST})\end{array}$ & 8 & 0 & 103 & 111 & 49 \\
\hline & & Belok Kanan (RT) & 8 & 0 & 75 & 83 & 38 \\
\hline & & Belok Kiri $\quad$ (LT) & 9 & 0 & 87 & 96 & 43 \\
\hline & & \multicolumn{4}{|c|}{ Total } & 289 & 130 \\
\hline \multirow{4}{*}{$\mathrm{S}$} & \multirow{4}{*}{$07.00-08.00$} & $\begin{array}{ll}\text { Lurus } & (\mathrm{ST}) \\
\end{array}$ & 10 & 0 & 117 & 127 & 57 \\
\hline & & Belok Kanan (RT) & 61 & 3 & 240 & 305 & 161 \\
\hline & & Belok Kiri $\quad$ (LT) & 33 & 1 & 181 & 214 & 106 \\
\hline & & & & & & 646 & 324 \\
\hline \multirow{4}{*}{$\mathrm{T}$} & \multirow{4}{*}{$07.00-08.00$} & $\begin{array}{ll}\text { Lurus } & (\mathrm{ST})\end{array}$ & 43 & 3 & 386 & 432 & 11 \\
\hline & & Belok Kanan (RT) & 8 & 0 & 146 & 154 & 124 \\
\hline & & Belok Kiri $\quad$ (LT) & 4 & 1 & 31 & 35 & 37 \\
\hline & & \multicolumn{4}{|c|}{ Total } & 620 & 172 \\
\hline
\end{tabular}

Analisa Koordinasi Sinyal Antar Simpang Dengan Menggunakan Software Transyt 14 - Aisyah Putri Elmanda ${ }^{1)}$, Zulfhazli ${ }^{2)}$, Said Jalalul Akbar ${ }^{3)}$ 


\begin{tabular}{|c|c|c|c|c|c|c|c|}
\hline \multirow{4}{*}{ B } & \multirow{4}{*}{$07.00-08.00$} & Lurus & 83 & 6 & 628 & 717 & 216 \\
\hline & & Belok Kanan (RT) & 10 & 0 & 73 & 83 & 25 \\
\hline & & Belok Kiri $\quad$ (LT) & 63 & 6 & 560 & 629 & 182 \\
\hline & & & & & & 1428 & 423 \\
\hline
\end{tabular}

Tabel 6 Arus lalu-lintas pada Simpang BPDjam puncak

\begin{tabular}{|c|c|c|c|c|c|c|c|}
\hline \multirow{2}{*}{ Pendekat } & \multirow{2}{*}{ Waktu } & \multirow{2}{*}{ Pergerakan } & \multicolumn{3}{|c|}{ Jenis Kendaran } & \multicolumn{2}{|c|}{ Volume } \\
\hline & & & LV & $\mathrm{HV}$ & $\mathrm{MC}$ & Kend & Smp \\
\hline \multirow{4}{*}{$\mathrm{U}$} & \multirow{4}{*}{$12.00-13.00$} & Lurus & 11 & 1 & 56 & 68 & 35 \\
\hline & & Belok Kanan (RT) & 20 & 2 & 61 & 82 & 46 \\
\hline & & Belok Kiri $\quad$ (LT) & 13 & 0 & 47 & 60 & 32 \\
\hline & & \multicolumn{4}{|c|}{ Total } & 210 & 113 \\
\hline \multirow{4}{*}{ S } & \multirow{4}{*}{$12.00-13.00$} & Lurus & 7 & 0 & 87 & 93 & 41 \\
\hline & & Belok Kanan (RT) & 8 & 0 & 38 & 46 & 23 \\
\hline & & Belok Kiri $\quad$ (LT) & 18 & 1 & 92 & 110 & 55 \\
\hline & & $\mathrm{Tc}$ & & & & 249 & 120 \\
\hline \multirow{4}{*}{$\mathrm{T}$} & \multirow{4}{*}{$12.00-13.00$} & Lurus & 84 & 3 & 460 & 548 & 179 \\
\hline & & Belok Kanan (RT) & 59 & 2 & 128 & 188 & 86 \\
\hline & & Belok Kiri $\quad(\mathrm{LT})$ & 47 & 2 & 52 & 100 & 59 \\
\hline & & $\mathrm{To}$ & & & & 833 & 324 \\
\hline \multirow{4}{*}{ B } & \multirow{4}{*}{$12.00-13.00$} & Lurus $\quad(\mathrm{ST})$ & 189 & 6 & 309 & 505 & 259 \\
\hline & & Belok Kanan (RT) & 36 & 1 & 88 & 124 & 54 \\
\hline & & Belok Kiri $\quad$ (LT) & 43 & 2 & 262 & 306 & 97 \\
\hline & & \multicolumn{4}{|c|}{ Total } & 935 & 411 \\
\hline
\end{tabular}

\subsection{EvaluasiKinerja SimpangKondisiEksisting}

Evaluasiyang dilakukan merupakan kondisi keseluruhan jaringan yang ditinjau untuk volume lalulintas rata-rata jam puncak.

Tabel 7 Hasil Evaluasi Kinerja Simpang Kondisi Eksisting

\begin{tabular}{|l|c|c|}
\hline \multicolumn{1}{|c|}{ Parameter } & Satuan & Besaran \\
\hline Degree of Saturation & $\%$ & 5,10 \\
Waktu tundaan/ delay rata-rata & Detik & 37,85 \\
Perhentian/ Stop rata-rata & $\%$ & 67,75 \\
Kecepatan perjalanan & $\mathrm{Km} / \mathrm{Jam}$ & 19,13 \\
Tingkat Pelayanan & - & $\mathrm{C}$ \\
\hline
\end{tabular}

\subsection{PerubahanWaktu SiklusDan Koordinasi}

Tabel 8 memperlihatkan optimasi waktu siklus dan koordinasi menghasilkan kinerja persimpangan yang lebih baik dibandingkan kondisi eksisting. Semua parameter yang ditinjau mengalami perubahan ke arah positif, seperti nilai DS yang diperoleh $83,93 \%$ telah memenuhi persyaratan Transyt 14 yang menetapkan nilai DS maksimal $90 \%$. Delay turun sebesar $26,38 \%$, stop juga turun sebesar36,23\%. Kecepatan perjalanan meningkat sebesar 59,08\%.

Tabel 8 Hasil Evaluasi Optimasi Waktu Siklus dan Offset

\begin{tabular}{|l|c|c|c|}
\hline \multicolumn{1}{|c|}{ Parameter } & Satuan & Besaran & Kondisi Eksisting \\
\hline Degree of Saturation & $\%$ & 83,93 & $-17,07$ \\
Waktu tundaan/ delay rata-rata & Detik & 26,38 & $-11,47$ \\
\hline
\end{tabular}




\begin{tabular}{|l|c|c|c|}
\hline Perhentian/ Stop rata-rata & $\%$ & 36,23 & $-20,57$ \\
Kecepatan perjalanan & $\mathrm{km} / \mathrm{jam}$ & 32,83 & 19,13 \\
Tingkat Pelayanan & - & $\mathrm{C}$ & $\mathrm{B}$ \\
\hline
\end{tabular}

Waktu siklus terbaik hasil iterasi adalah 100 detik yang menghasilkan PI terendah dan berada pada kondisi di bawah jenuh (DS<100\%).

Tabel 9 Durasi Fase Hijau Optimasi Waktu Siklus Simpang Empat

\begin{tabular}{|c|l|c|c|c|}
\hline Simpang & Pendekat & Waktu Mulai (s) & Waktu Akhir (s) & Durasi (s) \\
\hline \multirow{4}{*}{ I } & Utara & 14 & 22 & 8 \\
\cline { 2 - 5 } & Selatan & 63 & 87 & 24 \\
\cline { 2 - 5 } & Timur & 94 & 7 & 13 \\
\cline { 2 - 5 } & Barat & 29 & 56 & 27 \\
\hline
\end{tabular}

Tabel 10 Durasi Fase Hijau Optimasi Waktu Siklus Simpang BPD

\begin{tabular}{|c|l|c|c|c|}
\hline Simpang & Pendekat & Waktu Mulai (s) & Waktu Akhir (s) & Durasi (s) \\
\hline \multirow{3}{*}{ II } & Utara & 14 & 22 & 8 \\
\cline { 2 - 5 } & Selatan & 63 & 87 & 24 \\
\cline { 2 - 5 } & Timur & 94 & 7 & 13 \\
\cline { 2 - 5 } & Barat & 29 & 56 & 27 \\
\hline
\end{tabular}

\section{Kesimpulan dan Saran}

\subsection{Kesimpulan}

Terdapat beberapa hal yang dapat disimpulkan dari analisa dan perencanaan yang telah dilakukan bahwa:

1. Kedua simpang belum terkoordinasi, kondisi ini terlihat dari waktu siklus kedua simpang yang berbeda, di mana hal ini tidak memenuhi syarat sebagai simpang yang terkoordinasi.

2. Kinerja kondisi eksisting persimpangan Jalan Merdeka Kota Lhokseumawe berada pada tingkat layanan $C$ dengan degree of saturation $50,10 \%$, panjang, waktu tunda 46,00 detik, perhentian 67,75\%, dan kecepatan perjalanan 9,50 $\mathrm{km} / \mathrm{jam}$.

3. Kinerja persimpangan Jalan Merdeka Kota Lhokseumawe setelah dianalisa dengan menggunakan program transyt 14 berada pada tingkat layanan B dengan degree of saturation $83,93 \%$, panjang, waktu tunda 26,38 detik, perhentian 36,23\%,dan kecepatan perjalanan 32,83 km/jam.

4. Koordinasi antar simpang hasil optimasi waktu siklus dan offset menggunakan software Transyt 14 diperoleh waktu siklus efektif 100 detik, degree of saturation 83,93 turun sebesar $17,07 \%$.

5. Koordinasi juga berdampak pada waktu tunda menjadi 26,38 detik turun $69,70 \%$, perhentian $67,75 \%$ berkurang sebesar $20,57 \%$,dan kecepatan perjalanan menjadi $32,08 \mathrm{~km} / \mathrm{jam}$ meningkat 59,08\%.

6. Koordinasi dapat meningkatkan kinerja jaringan persimpangan menjadi tingkat pelayanan B.

\subsection{Saran}

Dari kesimpulan yang dipaparkan sebelumnya, terdapat beberapa saran yang diusulkan, diantaranya: 
1. Dari kesimpulan diatas terlihat bahwa kedua simpang belum terkoordinasi, untuk itu perlu dilakukan koordinasi karena memberikan beberapa keuntungan. Dengan koordinasi simpang, maka panjang antrian tidak mengganggu kendaraan yang melewati simpang pertama, dan juga tidak diperlukan lagi polisi untuk mengatur lalu-lintas setiap jam puncak (pagi dan sore).

2. Dari analisa kasus diatas, besarnya jumlah kendaraan tidak mampu ditampung oleh kapasitas simpang atau jalan yang ada. Seiring berjalannya waktu, jumlah kendaraan akan terus bertambah sedangkan kapasitas jalan tidak mungkin lagi untuk ditambah dan perubahan geometrik pun sulit untuk dilakukan. Untuk itu, perlu sebuah kebijakan serius dan tegas dari pemerintah untuk menekan pertambahan jumlah kendaraan.

3. Terdapat kekurangan dalam program transyt 14 yaitu tidak adanya output geometrik jalan pada program, sehingga terjadinya sedikit perbedaan selisih pada hasil hitungan dengan hasil dari program transyt 14 .

\section{Daftar Kepustakaan}

Ansyori Alamsyah, Alik, 2005, Rekayasa Lalu Lintas, Malang, UMM Press, Malang

Aminsyah, Muhammad, 2002, Optimalisasi Kinerja Lalu Lintas di Jaringan Jalan Utama Kota Padang, Padang

Anonim, 1997, Manual Kapasitas Jalan Indonesia (MKJI), Departemen Pekerjaan Umum, Indonesia

Bayasut, Emal Zain Muzambeh Tun, 2010, Analisa dan Koordinasi Sinyal Antar Simpang Pada Ruas Jalan Diponegoro Surabaya, Surabaya

Cahyaningrum, Fitria Purnayanti dan Ahmad Munawar, 2014, Kordinasi Simpang Bersinyal Pada Simpang Kentungan - Simpang Monjali Yogyakarta, Jogayakarta

Maulizar, dkk, 2014, Perencanaan Kordinasi Simpang Bersinyal (Studi Kasus Kota Lhokseumawe, Banda Aceh

Mc Shane, W.R dan Roess, R.P, 1998, Traffic Engineering 2nd Edition, New Jersey, Pretice Hall, Englewood Cliffs

Soedirdjo, Titi Liliani, 2002, Rekayasa Lalu Lintas, Direktorat Jenderal Pendidikan Tinggi Departemen Pendidikan Nasional, Bandung

Suadi, Nugroho, 2004, Kelayakan Pemasangan Lampu Lalu Lintas Terkoordinasi Di Kota Tegal, Tegal

Tamim, O. Z., 2008. Perencanaan, Pemodelan danRekayasa Transportasi.ITB, Bandung.

Zega, Maiman dan Medis S. Surbakti, 2015,Analisa Kordinasi Antar Simpang (Studi KasusJl Jamin Ginting - Jl Pattimura - Jl Mongonsidi, Medan 